ARTICLE

https://doi.org/10.1038/s41467-019-12993-x

\title{
Quasi $\mathrm{Pd}_{1} \mathrm{Ni}$ single-atom surface alloy catalyst enables hydrogenation of nitriles to secondary amines
}

Hengwei Wang1,2,4, Qiquan Luo (1) 1,4, Wei Liu³, Yue Lin (1) 1, Qiaoqiao Guan¹,2, Xusheng Zheng ${ }^{3}$, Haibin Pan 3 , Junfa Zhu (1) ${ }^{3}$, Zhihu Sun (iD ${ }^{3}$, Shiqiang Wei (i) ${ }^{3}$, Jinlong Yang (i) ${ }^{1,2} \&$ Junling Lu (i) ${ }^{1,2 *}$

Hydrogenation of nitriles represents as an atom-economic route to synthesize amines, crucial building blocks in fine chemicals. However, high redox potentials of nitriles render this approach to produce a mixture of amines, imines and low-value hydrogenolysis byproducts in general. Here we show that quasi atomic-dispersion of $\mathrm{Pd}$ within the outermost layer of $\mathrm{Ni}$ nanoparticles to form a $\mathrm{Pd}_{1} \mathrm{Ni}$ single-atom surface alloy structure maximizes the Pd utilization and breaks the strong metal-selectivity relations in benzonitrile hydrogenation, by prompting the yield of dibenzylamine drastically from $\sim 5$ to $97 \%$ under mild conditions $\left(80{ }^{\circ} \mathrm{C}\right.$; $0.6 \mathrm{MPa}$ ), and boosting an activity to about eight and four times higher than $\mathrm{Pd}$ and $\mathrm{Pt}$ standard catalysts, respectively. More importantly, the undesired carcinogenic toluene byproduct is completely prohibited, rendering its practical applications, especially in pharmaceutical industry. Such strategy can be extended to a broad scope of nitriles with high yields of secondary amines under mild conditions.

\footnotetext{
${ }^{1}$ Hefei National Laboratory for Physical Sciences at the Microscale, University of Science and Technology of China, Hefei 230026, P. R. China. ${ }^{2}$ Department of Chemical Physics, Key Laboratory of Surface and Interface Chemistry and Energy Catalysis of Anhui Higher Education Institutes, iChem, University of Science and Technology of China, Hefei 230026, P. R. China. ${ }^{3}$ National Synchrotron Radiation Laboratory, University of Science and Technology of China, Hefei 230029, P. R. China. ${ }^{4}$ These authors contributed equally: Hengwei Wang, Qiquan Luo. *email: junling@ustc.edu.cn
} 
A mong nitrogen-containing chemicals, amines are important and ubiquitous in various biological active compounds ${ }^{1,2}$, and are also valuable building blocks for synthesis of polymers, dyes, pharmaceuticals, agrochemicals, and fine chemicals in industry ${ }^{3-7}$. Compared with other functional compounds, synthesis of amines has received one of the most extensive attentions in organic chemistry ${ }^{3,8}$. Several methods such as amination of aryl and alkyl halides ${ }^{9-11}$, reductive amination of aldehydes and ketones ${ }^{12,13}$, amination of alcohols ${ }^{7,14}$ and hydroaminations of olefins ${ }^{6,15}$, have been developed to construct the carbon-nitrogen bonds for amines synthesis. However, these routes require either base additives or high cost, and also produce heavy liquid wastes in general. Alternatively, hydrogenation of readily available nitriles using molecular hydrogen over heterogeneous $^{16-23}$ and homogeneous ${ }^{5,24-26}$ metal catalysts has been recognized as a more environmentally benign and atomeconomic route to synthesis of these value-added amines. While, owing to the high redox potentials of nitriles, this process often shows severe selectivity issues, and generally produces mixtures of primary, secondary, and tertiary amines, imines and low-value hydrogenolysis by-products 4,27 , which makes this approach costly in the sequential products separation due to small differences in their boiling points ${ }^{28}$.

In the case of hydrogenation of benzonitrile $(\mathrm{BN})$, the formation of by-product toluene (TOL) is completely undesirable, not only because it lowers the atom economy, but also due to that TOL is carcinogenic ${ }^{29}$, which can be fatal for the applications of these contaminated benzylamine (BA) and dibenzylamine (DBA) in pharmaceutical industry. For examples, Pd catalysts often produce $\mathrm{BA}$ in majority, but also along with a considerable amount of TOL production ${ }^{16,19,20}$. Pt catalysts show a very different catalytic behavior, by producing DBA as the major product instead, and also along with a few percentage of TOL formation $16,21,22$. Transition metal Ni catalysts are also investigated, but show relatively lower hydrogenation activity even under much higher hydrogen pressures; therein, a mixture of BA, $\mathrm{DBA}$, and the N-benzylidenebenzylamine (DBI) are generally observed $^{30,31}$. The nature of metal catalysts appears to be the crucial factor that governs the reaction selectivity $4,28,32$. Alloying Pd with Ir was shown to be capable of tailoring the product selectivity to a large extend, but still generating an appreciable amount of toxic TOL by-product of $\sim 8 \%{ }^{32}$. Incorporation of additives (such as ammonia, $\mathrm{NaOH}, \mathrm{HCl}$, acetic acid, $\mathrm{NaH}_{2} \mathrm{PO}_{4}$ et al.) is helpful to prompt primary amine formation $19,28,31,33$. However, such additive process would lead to equipment corrosion issues and raise of the cost for products purification, in addition, the formation of toluene is still inevitable ${ }^{19}$. Recently, hydrogenation of nitriles using a supercritical $\mathrm{CO}_{2} / \mathrm{H}_{2} \mathrm{O}$ biphasic solvent and transfer hydrogenation of nitriles with ammonia borane or $\mathrm{HCOOH}$ in triethylamine as hydrogen source were reported for selective hydrogenation of nitriles to primary or secondary amines ${ }^{34-37}$, while these routes both suffer from high cost due to either the harsh operation pressure or the high cost of the hydrogen source (or solvent). Therefore, it is still an urgent need to develop a heterogeneous catalyst to produce only one of these amines selectively along with complete inhibition of hydrocarbons by-product under a mild and facile reaction condition. Among these protocols, direct hydrogenation of nitriles to secondary amines is particularly desirable, but much more challenging, because of the involvement of complex reaction networks and strong metal-selectivity relations ${ }^{4,32,38}$.

Inspired by maximized noble metal utilization in core-shell bimetallic catalysts and the unique coordination and electronic environment in single-atom alloy (SAA) catalysts ${ }^{39-45}$, here we report that selective deposition of Pd on silica supported Ni NPs at low coverages using atomic layer deposition (ALD) produces quasi atomically dispersed $\mathrm{Pd}$ within the outermost layer of $\mathrm{Ni}$ particles to form a core-shell like quasi $\mathrm{Pd}_{1} \mathrm{Ni}$ single-atom surface alloy (SASA) structure as confirmed by detailed microscopic and spectroscopic characterization. The resulting isolated $\mathrm{Pd}$ atoms and the surrounding $\mathrm{Ni}$ atoms act in synergy, break the strong metal-selectivity relations in hydrogenation of $\mathrm{BN}$, and prompt the yield of DBA drastically from $\sim 5$ to $97 \%$ under mild conditions $\left(80^{\circ} \mathrm{C}\right.$; $\left.0.6 \mathrm{MPa}\right)$; meanwhile, the carcinogenic TOL byproduct is below the detection limit, rendering its practical applications, especially in pharmaceuticals ${ }^{46}$, e.g. penicillin ${ }^{47}$. In addition, the activity was also about eight and four times higher than those of monometallic $\mathrm{Pd}$ and $\mathrm{Pt}$ catalysts, respectively. Theoretical calculations unveil that the strong synergy between isolated Pd atoms and Ni significantly extend the resident time of $\mathrm{BI}$ intermediate on $\mathrm{Pd}_{1} \mathrm{Ni}$ surface, thus stimulating the exclusive formation of DBA. This method can be extended to a broad scope of nitriles to achieve secondary amines with high yields above 94\% under mild conditions, shedding light for controlling the selectivity in hydrogenation of nitriles.

\section{Results and discussion}

Synthesis and morphology of PdNi bimetallic catalysts. A set of $\mathrm{PdNi} / \mathrm{SiO}_{2}$ bimetallic catalysts with different $\mathrm{Pd}$ dispersions were precisely fabricated using a method by combining wet chemistry and ALD (Supplementary Fig. 1). A Ni/SiO ${ }_{2}$ catalyst with an average particle size of $3.4 \pm 0.7 \mathrm{~nm}$ was first prepared using the deposition-precipitation (DP) method (Supplementary Fig. 2) ${ }^{48}$. After that, with the strategy of low-temperature selective deposition for bimetallic NP synthesis we developed recently ${ }^{49-51}$, Pd ALD was executed on the $\mathrm{Ni} / \mathrm{SiO}_{2}$ catalyst at $150{ }^{\circ} \mathrm{C}$ to deposit $\mathrm{Pd}$ selectively on the surface of Ni NPs without any nucleation on $\mathrm{SiO}_{2}$ support (Fig. 1a) ${ }^{50}$. At low Pd coverages, the highly dispersed $\mathrm{Pd}$ atoms might become a part of $\mathrm{Ni}$ surface lattice to minimize the surface energies (the middle of Fig. 1a). Varying the number of ALD cycles tailors the Pd coverage on Ni NPs precisely. The resulting samples are denoted as $x \mathrm{Pd}-\mathrm{Ni} / \mathrm{SiO}_{2}$, where $x$ represents the number of ALD cycles.

Inductively coupled plasma atomic emission spectroscopy (ICP-AES) analysis (Fig. 1b and Supplementary Table 1) and energy-dispersive spectroscopy (EDS) elemental mapping (Fig. 1c-f) both unambiguously confirmed the selective deposition of $\mathrm{Pd}$ on $\mathrm{Ni}$ NPs. Figure $1 \mathrm{~g}$ shows a representative aberration-corrected high-angle annular dark-field scanning transmission electron microscopy (HAADF-STEM) image of $5 \mathrm{Pd}-\mathrm{Ni} / \mathrm{SiO}_{2}$. Due to the much larger $\mathrm{Z}$ value of $\mathrm{Pd}$ than $\mathrm{Ni}$, brighter spots highlighted by the yellow arrows in Fig. 1g and Supplementary Fig. 3, along with the intensity profile in Fig. 1h, suggest that Pd atoms were atomically dispersed on the partially oxidized Ni NPs, which might be caused by air exposure during sample transfer. On $20 \mathrm{Pd}-\mathrm{Ni} / \mathrm{SiO}_{2}$, large $\mathrm{Pd}$ ensembles (or even continuous shell) were formed on Ni NPs, as indicated by the brighter shell in Fig. $1 \mathrm{i}$ and the line profile analysis in Fig. 1j, k.

Catalytic performance. Selective hydrogenation of BN was conducted in a batch reactor at $80^{\circ} \mathrm{C}$ using ethanol as the solvent under a $\mathrm{H}_{2}$ pressure of $0.6 \mathrm{MPa}$. A $\mathrm{Pd} / \mathrm{SiO}_{2}$ sample with a $\mathrm{Pd}$ particle size of $3.2 \pm 0.3 \mathrm{~nm}$ (Supplementary Fig. 4) was first evaluated. It required $\sim 10 \mathrm{~h}$ to complete the reaction (Fig. $2 \mathrm{a}$ ). The selectivity of BA was about $74 \%$ at the earlier stage, but considerably decreased with time. The selectivity of DBA and the undesired hydrogenolysis by-product TOL were about 5 and $21 \%$, respectively, consistent with literature (Supplementary Table 2) $16,19,20$. When conversion was above $90 \%$, the selectivity of TOL increased rapidly to $36 \%$ at the expense of the $\mathrm{BA}$, indicating the hydrogenolysis reaction of BA to TOL. Decreasing the reaction temperature from 80 to $60{ }^{\circ} \mathrm{C}$ 
a
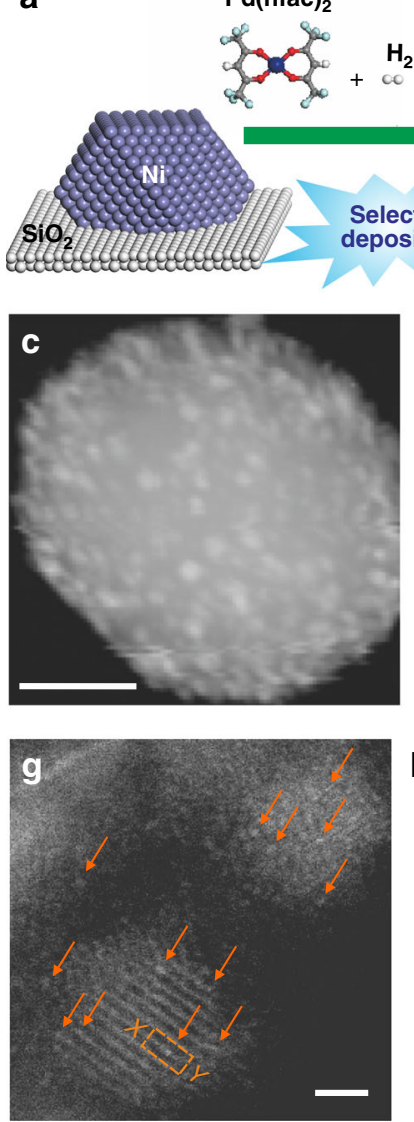

$\mathrm{H}_{2}$

Pd ALD
Multiple ALD cycles

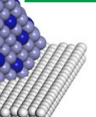

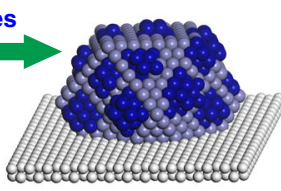

b

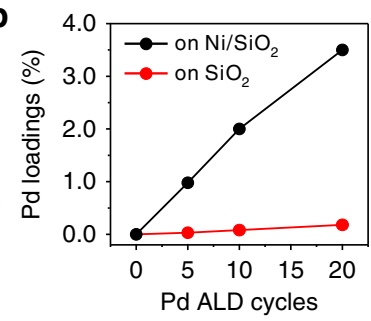

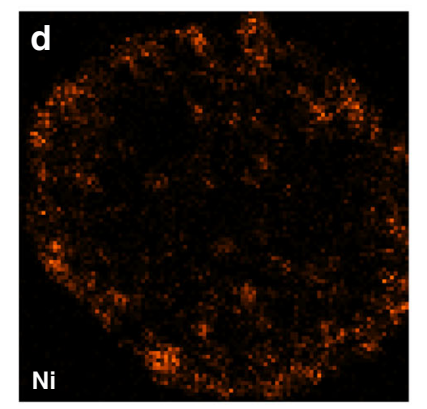
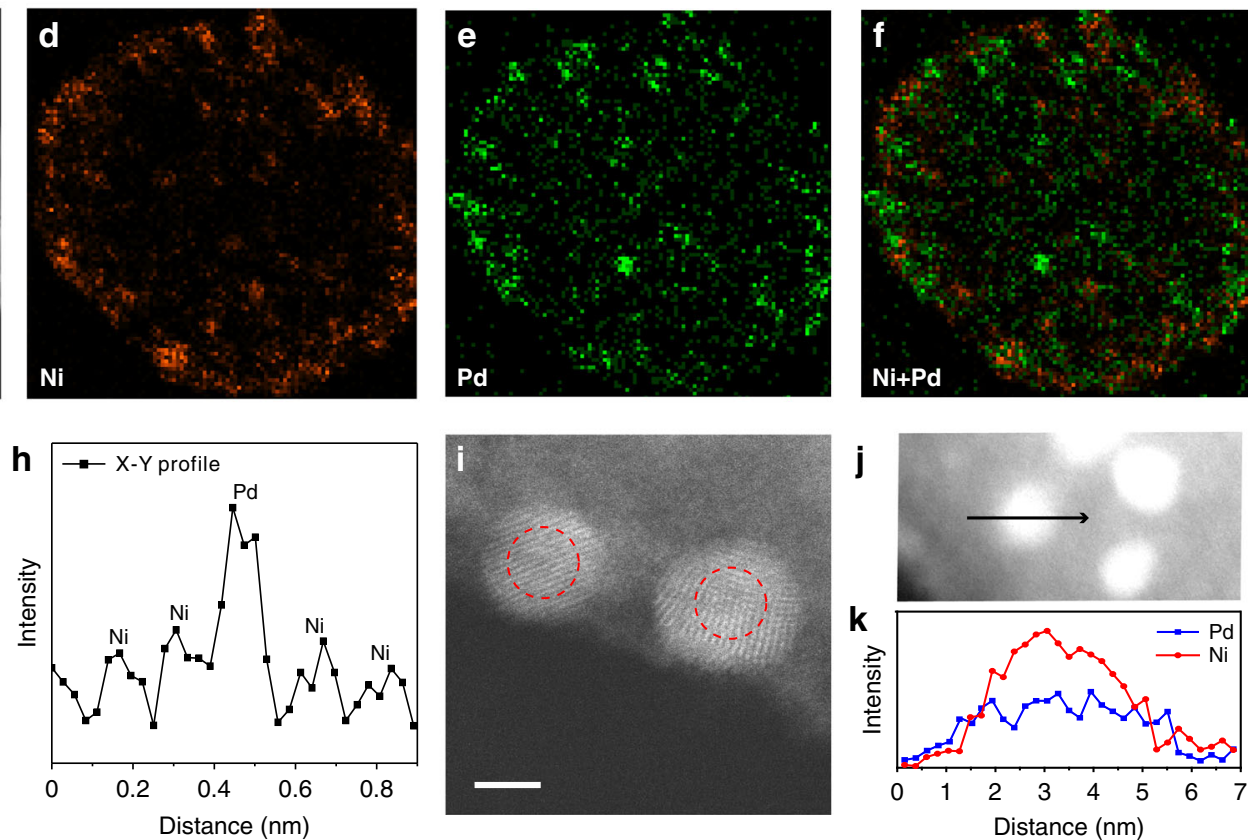

Fig. 1 Synthesis and morphologies of $x \mathrm{Pd}-\mathrm{Ni} / \mathrm{SiO}_{2}$ bimetallic catalysts. a Schematic illustration of synthesis of $x \mathrm{Pd}-\mathrm{Ni} / \mathrm{SiO}_{2}$ bimetallic catalysts using selective $\mathrm{Pd} A L D$. $\mathbf{b} \mathrm{Pd}$ loadings in the $x \mathrm{Pd}-\mathrm{Ni} / \mathrm{SiO}_{2}$ and $x \mathrm{Pd} / \mathrm{SiO}_{2}$ samples determined by ICP-AES. c STEM image of $20 \mathrm{Pd}-\mathrm{Ni} / \mathrm{SiO} 2$ and the corresponding EDS elemental mapping signals: $\mathrm{Ni} \mathrm{K \alpha}(\mathbf{d}), \mathrm{Pd} L \alpha(\mathbf{e})$ and the constructed $\mathrm{Ni}+\mathrm{Pd}(\mathbf{f})$. Scale bar in $\mathbf{c} 20 \mathrm{~nm}$. $\mathbf{g}$ A representative HAADF-STEM image of 5Pd$\mathrm{Ni} / \mathrm{SiO}_{2}$. Isolated $\mathrm{Pd}$ single atoms on partially-oxidized Ni NPs were highlighted by brown arrows. Scale bar: $2 \mathrm{~nm}$. $\mathbf{h}$ Intensity profile along the line $\mathrm{X}-\mathrm{Y}$ in $\mathbf{g}$ highlighting the presence of Pd single atoms. $\mathbf{i}$ A representative HAADF-STEM image of $20 \mathrm{Pd}-\mathrm{Ni} / \mathrm{SiO}_{2}$. Scale bar: $2 \mathrm{~nm}$. The red circles in $\mathbf{i}$ highlight contrast of the inner core and outer shell of the NPs. $\mathbf{j}$ A STEM image of 2OPd-Ni/SiO $2 . \mathbf{k}$ EDS line profile analysis across the NP in $\mathbf{j}$

or increasing hydrogenation pressure to $1 \mathrm{MPa}$ did not change the products distribution significantly (Supplementary Table 3). A Pt/SiO ${ }_{2}$ catalyst (Supplementary Fig. 5), the well-documented catalyst to produce $\mathrm{DBA}^{16,21,22}$, was also evaluated under the same conditions. It was found that the reaction completed in $9 \mathrm{~h}$ (Fig. 2b) with a DBA selectivity of only $\sim 73 \%$. The TOL selectivity was also as high as $11 \%$, consistent with literature (Supplementary Table 2) ${ }^{16,21,22}$.

On the $5 \mathrm{Pd}-\mathrm{Ni} / \mathrm{SiO}_{2}$ sample, the reaction proceeded much quicker, and completed in only $\sim 3 \mathrm{~h}$ (Fig. 2c). Very surprisingly, the distribution of products changed completely; therein DBA became the major product, with a selectivity as high as $\sim 97 \%$ in the entire range of $\mathrm{BN}$ conversions, leading to a high yield of DBA up to $97 \%$. In contrast, BA was decreased sharply to only $\sim 3 \%$, and the undesired hydrogenolysis path to TOL was below the detection limit in the entire range of conversion. More importantly, after the reaction was completed, prolonging the reaction to another $3 \mathrm{~h}$ did not alter the DBA selectivity considerably, much better than $\mathrm{Pd} / \mathrm{SiO}_{2}$ and $\mathrm{Pt} / \mathrm{SiO}_{2}$ (Fig. 2a,b), indication of an effective inhibition of hydrogenolysis of amines to hydrocarbons. Increase of the reaction temperature to $120^{\circ} \mathrm{C}$ or the $\mathrm{H}_{2}$ pressure to $1 \mathrm{MPa}$ would reduce the DBA selectivity slightly, while TOL was still effectively prohibited in both cases (Supplementary Table 4). On the other hand, we found that variation of solvents did not change the DBA selectivity considerably, different from the literature ${ }^{52}$, although the activity became slightly lower in non-alcoholic solvents (Supplementary Table 5). This result suggests that the high DBA selectivity achieved on $5 \mathrm{Pd}-\mathrm{Ni} / \mathrm{SiO}_{2}$ catalyst is solely due to the synergy in $\mathrm{Pd}_{1} \mathrm{Ni}$ SASA, rather than the solvent effect. These robust catalytic behaviors under different conditions render it convenient for practical operation in a large scale.

Calculations of turnover frequencies (TOFs) reveal that the $5 \mathrm{Pd}$ $\mathrm{Ni} / \mathrm{SiO}_{2}$ sample exhibited a highest TOF of $515 \mathrm{~h}^{-1}$, which was about eight and four times higher than $\mathrm{Pd} / \mathrm{SiO}_{2}\left(64 \mathrm{~h}^{-1}\right)$ and $\mathrm{Pt} /$ $\mathrm{SiO}_{2}\left(127 \mathrm{~h}^{-1}\right)$, respectively, as shown in Fig. $2 \mathrm{~d}$. Moreover, the remarkable activity and selectivity achieved on $5 \mathrm{Pd}-\mathrm{Ni} / \mathrm{SiO}_{2} \mathrm{SASA}$ were both much superior than those Pd-, Pt-, Rh-, and Ir-based catalysts reported in literatures (Supplementary Table 2). To note that the conversion of $\mathrm{BN}$ was about only $2.6 \%$ after $3 \mathrm{~h}$ on the $\mathrm{Ni}$ / $\mathrm{SiO}_{2}$ sample under the same reaction conditions (Supplementary Fig. 6). Recyclability of $5 \mathrm{Pd}-\mathrm{Ni} / \mathrm{SiO}_{2}$ was further evaluated, it was found that no significant decay in both selectivity and activity was observed even after the catalyst was recycled for eight times without further calcination/reduction treatments in between (Fig. 2e), indicating the absence of any poisoning or coking. STEM measurements of the recycled sample further confirmed the persistence of the high dispersion of $\mathrm{Pd}$ on $\mathrm{Ni}$ particles in majority as that in the fresh samples (Supplementary Fig. 7). Accordingly, $5 \mathrm{Pd}-\mathrm{Ni} / \mathrm{SiO}_{2}$ catalyst was highly active and stable during $\mathrm{BN}$ hydrogenation, thereby exhibiting potential practical applications, especially in pharmaceuticals ${ }^{46}$, e.g. penicillin ${ }^{47}$. 

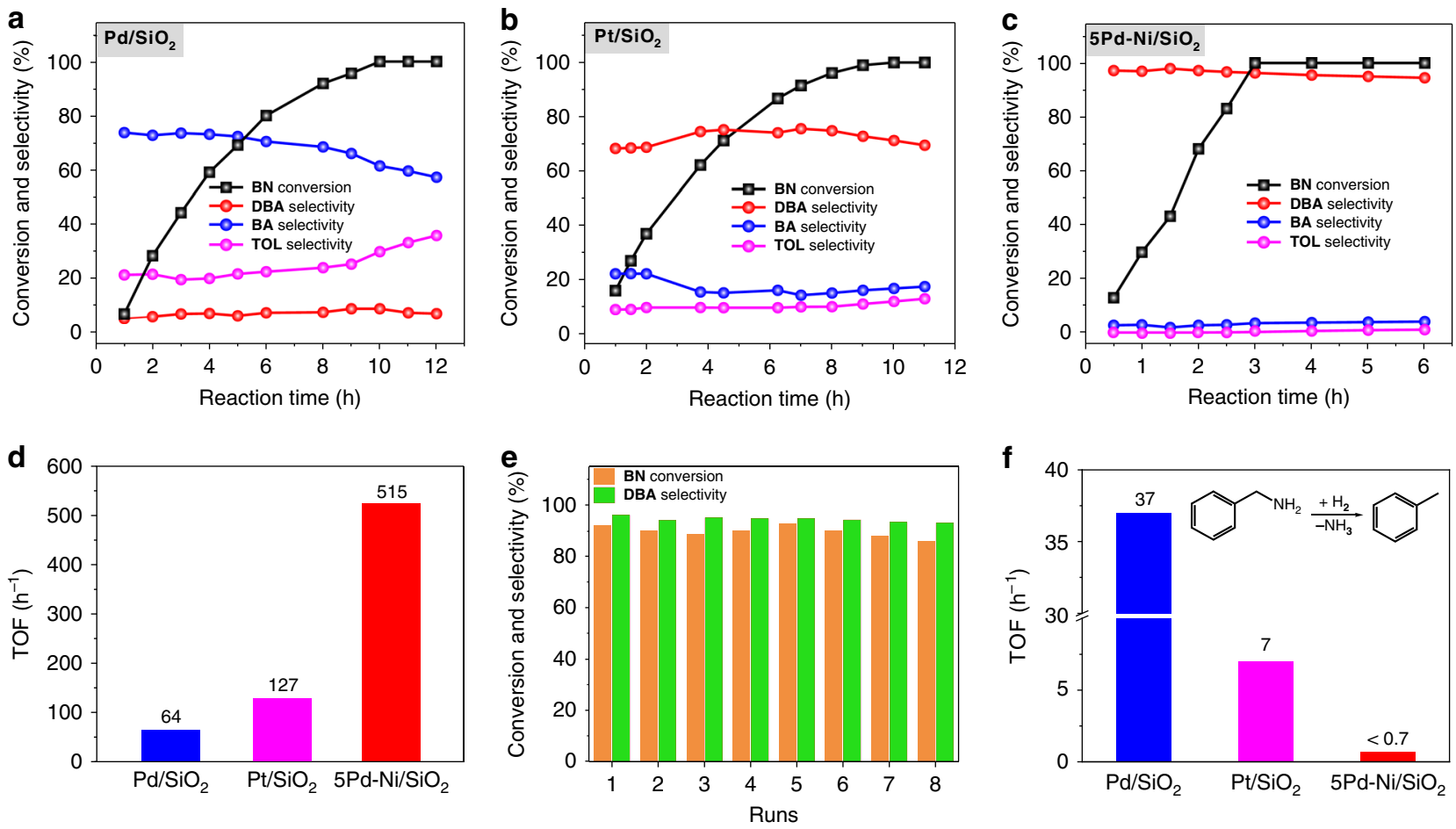

Fig. 2 Catalytic performances of $\mathrm{Pd} / \mathrm{SiO}_{2}, \mathrm{Pt} / \mathrm{SiO}_{2}$, and $5 \mathrm{Pd}-\mathrm{Ni} / \mathrm{SiO}_{2}$ catalysts in hydrogenation of $\mathrm{BN}$ and hydrogenolysis of $\mathrm{BA}$. Time profiles of hydrogenation of $\mathrm{BN}$ over $\mathrm{Pd} / \mathrm{SiO}_{2}(\mathbf{a}), \mathrm{Pt} / \mathrm{SiO}_{2}(\mathbf{b})$ and $5 \mathrm{Pd}-\mathrm{Ni} / \mathrm{SiO}_{2}(\mathbf{c})$, and their corresponding $\mathrm{TOFs}$ (d). Reaction conditions: solvent, ethanol, $60 \mathrm{~mL}$; $\mathrm{BN}, 0.5 \mathrm{~g}$; catalyst, $30 \mathrm{mg} ; \mathrm{H}_{2}$ pressure, $0.6 \mathrm{MPa}$; temperature, $80^{\circ} \mathrm{C}$. e Recyclability test of the $5 \mathrm{Pd}-\mathrm{Ni} / \mathrm{SiO}_{2}$ sample. Reaction conditions: solvent, ethanol, $60 \mathrm{~mL}$; BN, $1 \mathrm{~g}$; catalyst, $100 \mathrm{mg}$; $\mathrm{H}_{2}$ pressure, $0.6 \mathrm{MPa}$; temperature, $80^{\circ} \mathrm{C}$; reaction time, $2 \mathrm{~h}$. The larger amount of substrate and catalyst here is only for a purpose of the convenience of recycling. $\mathbf{f}$ Time profiles of hydrogenolysis of $\mathrm{BA}$ over $\mathrm{Pd} / \mathrm{SiO}_{2}, \mathrm{Pt} / \mathrm{SiO}_{2}$ and $5 \mathrm{Pd}-\mathrm{Ni} / \mathrm{SiO} \mathrm{O}_{2}$. Reaction conditions: solvent, ethanol, $60 \mathrm{~mL}$; $\mathrm{BA}, 0.5 \mathrm{~g}$; catalyst, $30 \mathrm{mg}$; $\mathrm{H}_{2}$ pressure, $0.6 \mathrm{MPa}$; temperature, $80^{\circ} \mathrm{C}$

Lennon et al. proposed that the TOL formation stems from hydrogenolysis of $\mathrm{BA}$ on $\mathrm{Pd}$ catalyst, which takes place independently from $\mathrm{BN}$ hydrogenation ${ }^{20}$. To get a better understanding of the inhibition of TOL formation on $5 \mathrm{Pd}-\mathrm{Ni}$ / $\mathrm{SiO}_{2}$ in $\mathrm{BN}$ hydrogenation, the $\mathrm{BA}$ hydrogenolysis reaction was further performed on these three samples under the same conditions. It was found that $\mathrm{BA}$ hydrogenolysis was negligible on $5 \mathrm{Pd}-\mathrm{Ni} / \mathrm{SiO}_{2}$, but much facile on $\mathrm{Pd} / \mathrm{SiO}_{2}$ and $\mathrm{Pt} / \mathrm{SiO}_{2}$ (Fig. 2f), unambiguously confirming the effective inhibition of the TOL formation.

Increasing the Pd coverage on $\mathrm{Ni}$ decreased the TOF and the yield of DBA considerably by forming more BA product (Supplementary Fig. 8). For instance, on $20 \mathrm{Pd}-\mathrm{Ni} / \mathrm{SiO}_{2}$, the yield of DBA reduced to $77 \%$, along with a BA yield of $21 \%$. According to the catalytic behavior of $\mathrm{Pd} / \mathrm{SiO}_{2}$ (Fig. 2a), the increase of the $\mathrm{BA}$ yield on $20 \mathrm{Pd}-\mathrm{Ni} / \mathrm{SiO}_{2}$ is attributed to the formation of large $\mathrm{Pd}$ ensembles at high converges (Fig. 1), providing solid evidence that isolation of $\mathrm{Pd}$ with $\mathrm{Ni}$ plays the key role for the exclusive DBA formation on $5 \mathrm{Pd}-\mathrm{Ni} / \mathrm{SiO}_{2}$. However, the TOL formation was still trivial on all PdNi samples (Supplementary Figs. 8 and 9).

Besides above, we found that selective hydrogenation of $\mathrm{BN}$ over $x \mathrm{Pt}-\mathrm{Ni} / \mathrm{SiO}_{2}(x=1,3)$ bimetallic catalysts, synthesized in a similar manner with $x \mathrm{Pd}-\mathrm{Ni} / \mathrm{SiO}_{2}$, also showed remarkable activity improvements and efficient inhibition of TOL formation (Supplementary Table 6). However, over these PtNi bimetallic catalysts, DBI was the major product ( $>70 \%$ selectivity) instead, sharply different from $x \mathrm{Pd}-\mathrm{Ni} / \mathrm{SiO}_{2}$.

Structural characterization of PdNi bimetallic catalysts. To establish structure-activity relations, in situ X-ray adsorption finestructure (XAFS) measurements were first performed on the $x \mathrm{Pd}$ -
$\mathrm{Ni} / \mathrm{SiO}_{2}$ samples $(x=5,10$, and 20$)$ at the Pd $K$-edge to investigate the detailed coordination environments of $\mathrm{Pd}$ in $\mathrm{PdNi}$ bimetallic NPs (Supplementary Figs. 10-12 and Supplementary Note 1). Fourier transforms of the extended X-ray absorption fine structure (EXAFS) spectra of various samples in the real space are shown in Fig. 3a. After in situ $\mathrm{H}_{2}$ reduction at $150{ }^{\circ} \mathrm{C}$, the EXAFS spectrum of $5 \mathrm{Pd}-\mathrm{Ni} / \mathrm{SiO}_{2}$ exhibited a dominant peak at $2.12 \AA$, mainly attributed to Pd-Ni coordination ${ }^{53,54}$. EXAFS curve fittings revealed that the $\mathrm{Pd}-\mathrm{Ni}$ coordination is the dominant one with a coordination number $(\mathrm{CN})$ of 5.5 , while the Pd-Pd coordination has a minor contribution with a $\mathrm{CN}$ of only 1.2 (Supplementary Figs. 11a and 12a, and Supplementary Table 7), suggesting that $\mathrm{Pd}$ atoms are atomically dispersed in majority, in line with the HAADF-STEM observation (Fig. 1g). When the Pd atoms were uniformly distributed over both the surface and the bulk of Ni NPs, it is expected that the Pd-Ni CN will be significantly higher than the average $\mathrm{CN}$ for surface atoms ${ }^{40,55}$. In our case, the surface $\mathrm{Ni}$ atoms in a $3.4-\mathrm{nm}$ Ni NP have an average $\mathrm{Ni}-\mathrm{Ni} \mathrm{CN}$ of 7.8 , according to the cubic-octahedral cluster model $^{56}$. Thus the lower $\mathrm{CN}$ of 5.5 for $\mathrm{Pd}-\mathrm{Ni}$ suggests that the isolated $\mathrm{Pd}$ atoms were within the outermost layer of $\mathrm{Ni}$ particles in majority to form a core-shell like quasi $\mathrm{Pd}_{1} \mathrm{Ni}$ SASA structure (the inset of Fig. 3a). To note that this structure with maximized Pd utilization, is sharply different from those SAAs in literature where the isolated secondary metal atoms (B) are rather uniformly dispersed within the primary metal (A) particles with a large CN of A-B bond (often greater than 9) $40,45,55,57$.

As increasing the Pd coverage, the peak splits into two peaks at 2.15 and $2.52 \AA$, assigned to the $\mathrm{Pd}-\mathrm{Ni}$ and $\mathrm{Pd}-\mathrm{Pd}$ coordinations, respectively ${ }^{53,54}$. EXAFS curve fittings showed that the $\mathrm{CNs}$ of $\mathrm{Pd}-\mathrm{Ni}$ coordination decreased to 4.3 and 2.7 , while the $\mathrm{Pd}-\mathrm{Pd}$ coordination increased to 3.6 and 6.6 for $10 \mathrm{Pd}-\mathrm{Ni} / \mathrm{SiO}_{2}$ and 

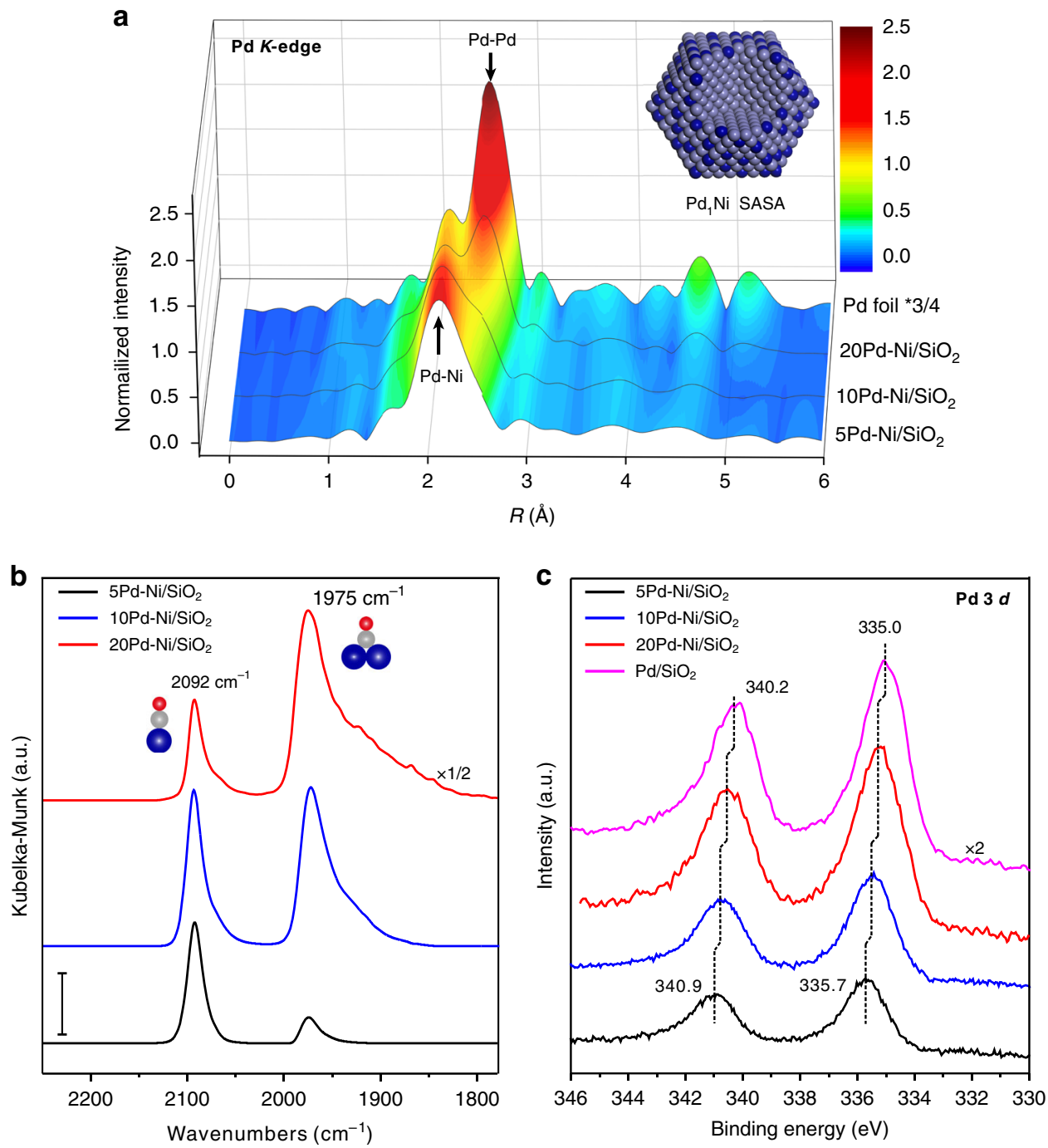

Fig. 3 Structural characterization of $x \mathrm{Pd}-\mathrm{Ni} / \mathrm{SiO}_{2}$ bimetallic catalysts. a In situ Fourier transforms EXAFS spectra of the $x \mathrm{Pd}-\mathrm{Ni} / \mathrm{SiO} \mathrm{O}_{2}$ samples $(x=5,10$, and 20 ) and $\mathrm{Pd}$ foil reference in the real space at the $\mathrm{Pd} K$-edge. A model of core-shell like $\mathrm{Pd}_{1} \mathrm{Ni} \mathrm{SASA}$ structure for $5 \mathrm{Pd}-\mathrm{Ni} / \mathrm{SiO} \mathrm{O}_{2}$ is illustrated as the inset in $\mathbf{a}$, where the dark blue and light blue balls are Pd and Ni atom, respectively. $\mathbf{b}$ DRIFTS CO chemisorption of the $x \mathrm{Pd}-\mathrm{Ni} / \mathrm{SiO} \mathrm{S}_{2} \mathrm{samples}(x=5,10$, and 20$)$ at the $\mathrm{CO}$ saturation coverage. The dark blue, gray, and red balls in $\mathbf{b}$ are $\mathrm{Pd}, \mathrm{C}$, and $\mathrm{O}$ atom, respectively. Scale bar: 0.01 . c In situ XPS spectra of $x \mathrm{Pd}-\mathrm{Ni} / \mathrm{SiO} \mathrm{O}_{2}$ samples $(x=5,10$, and 20$)$ and a $\mathrm{Pd} / \mathrm{SiO}_{2}$ reference in the $\mathrm{Pd} 3 d$ region

20Pd-Ni/SiO 2 , respectively (Supplementary Figs. $11 \mathrm{~b}, \mathrm{c}$, and $12 \mathrm{~b}$, c, and Supplementary Table 7). These results describe the evolution of $\mathrm{Pd}$ species on $\mathrm{Ni}$ from quasi atomically dispersed $\mathrm{Pd}$ atoms to large Pd ensembles or even continuous Pd shell, consistent excellently with the STEM observation (Fig. 1).

To further explore the surface structure of PdNi bimetallic NPs, in situ diffuse reflectance infrared Fourier transform spectroscopy (DRIFTS) CO chemisorption measurements were also performed on these samples, since $\mathrm{CO}$ is a well-known sensitive probe of $\mathrm{Pd}$ ensemble structures ${ }^{50,58-62}$. In this work, after $\mathrm{CO}$ exposure, $\mathrm{O}_{2}$ purging was employed to remove chemisorbed $\mathrm{CO}$ on $\mathrm{Ni}$, so that the CO on Pd can be illustrated individually (See Supplementary Fig. 13 and Supplementary Note 2 for details). As shown in Fig. 3b, on $5 \mathrm{Pd}-\mathrm{Ni} / \mathrm{SiO}_{2}$, the dominant peak at $2092 \mathrm{~cm}^{-1}$, assigned to the linear $\mathrm{CO}$ on $\mathrm{Pd}$, was much stronger than the bridge-bonded CO peak at $1975 \mathrm{~cm}^{-1}$, thus again implying that $\mathrm{Pd}$ was isolated by the surrounding $\mathrm{Ni}$ atoms in majority $50,60,63$, which agrees excellently with the EXAFS results in Fig. $3 a$ and the STEM observation (Fig. 1g). As increase of Pd ALD cycles, the bridge-bonded CO peak developed aggressively, clearly demonstrating the formation of large Pd ensembles or continuous Pd shell on the surface of $\mathrm{Ni}$
NPs in these two samples ${ }^{50}$. In situ X-ray photoemission spectroscopy (XPS) measurements in the Pd $3 d$ region disclosed a strong electronic interaction between $\mathrm{Pd}$ and $\mathrm{Ni}$ (Fig. 3c). On $5 \mathrm{Pd}-\mathrm{Ni} / \mathrm{SiO}_{2}$, we observed a remarkable upwards shift of $\mathrm{Pd} 3 d$ binding energy by $0.7 \mathrm{eV}$ with respect to that of $\mathrm{Pd} / \mathrm{SiO}_{2}$, which is attributed to the charge transfer between $\mathrm{Pd}$ and $\mathrm{Ni}^{64-66}$. The upwards shift gradually became less pronounced as increasing the Pd coverage, implying the surface electronic structure was tending to pure $\mathrm{Pd}$, in line with literature ${ }^{50,66-68}$. In brief, the remarkable activity improvements and selectivity tailoring in Fig. 2 and Supplementary Figs. 8 and 9 are attributed to the ensemble and electronic structure of $\mathrm{Pd}$ on $\mathrm{Ni}$.

Theoretical insight of hydrogenation of $\mathrm{BN}$ on metals. Adamczyk et al. very recently reported detailed calculations of hydrogenation of acetonitrile on $\mathrm{Pd}$ and Co catalysts ${ }^{69-71}$. However, to our knowledge, theoretical calculations of hydrogenation of $\mathrm{BN}$ on metals have not been reported yet. Here, firstprinciples DFT calculations on $\mathrm{Pd}(111)$ and $\mathrm{Pt}(111)$ surfaces were first performed to elucidate the underlying mechanism (Fig. 4 and Supplementary Figs. 14-18). In this work, we only considered the 
a

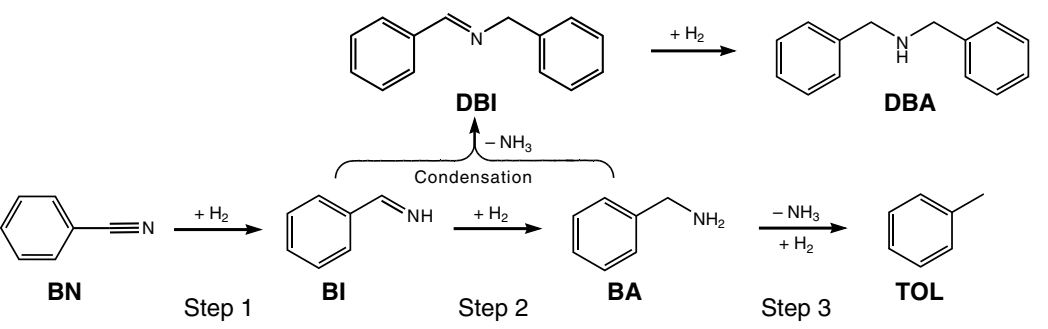

b

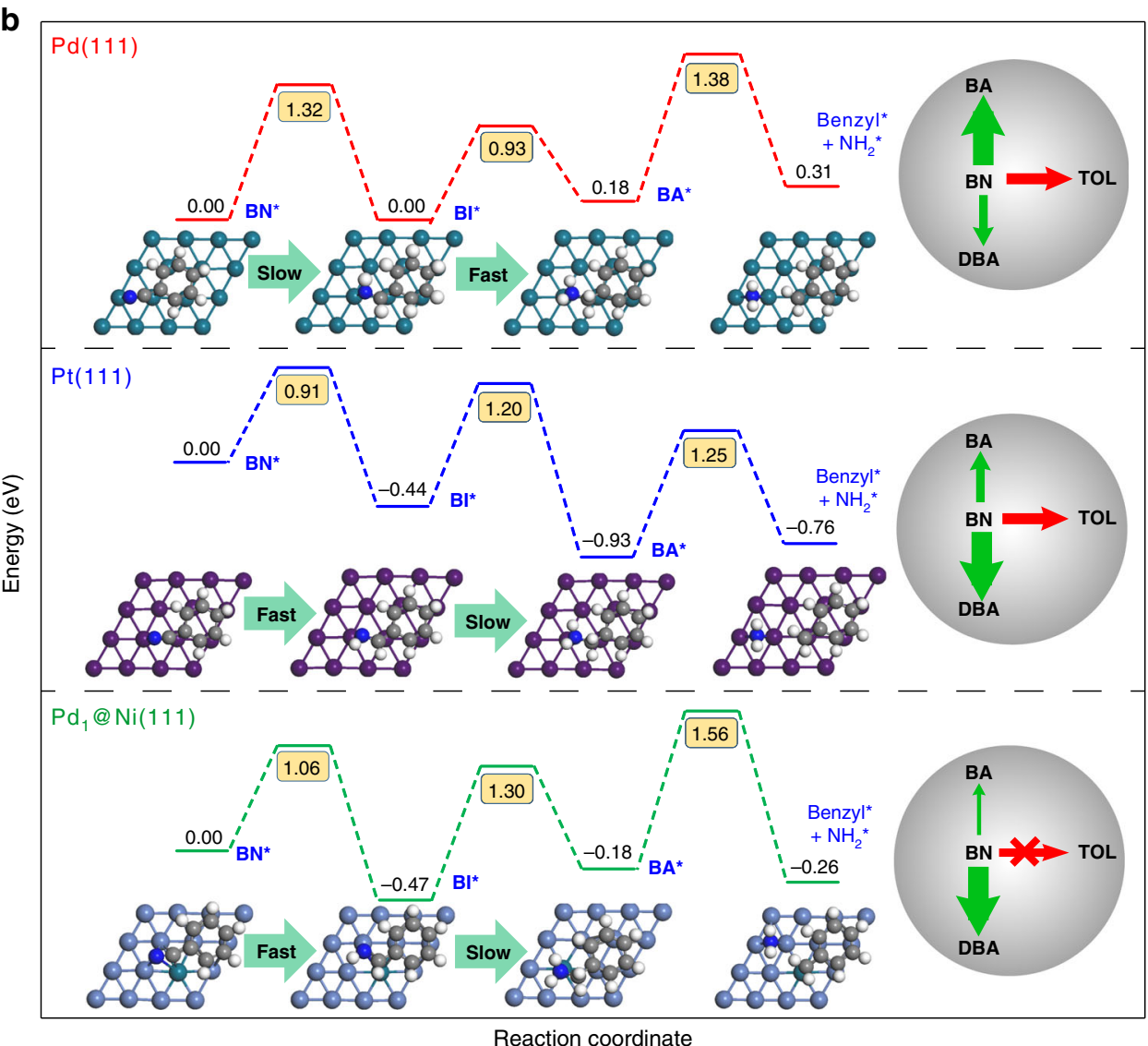

Fig. 4 The reaction paths of hydrogenation of BN on metal surfaces. a Reaction pathways of hydrogenation of BN. $\mathbf{b}$ Energy profiles of the key intermediates and transition states involved in $\mathbf{a}$ on $\mathrm{Pd}(111), \mathrm{Pt}(111)$, and $\mathrm{Pd}_{1} @ \mathrm{Ni}(111)$ surfaces. The energy barriers of the consecutive hydrogenation and hydrogenolysis steps are highlighted by the yellow squires. The Pd, Pt, Ni, C, N, and $\mathrm{H}$ atoms are shown in green, violet, light blue, gray, blue, and white, respectively. On the right side of $\mathbf{b}$, the product distribution over the corresponding metal surfaces was highlighted, where the thicker the arrows represents the higher selectivity

reaction pathways of $\mathrm{BN}$ hydrogenation to $\mathrm{BA}$ and the subsequent $\mathrm{BA}$ hydrogenolysis to TOL; while the condensation reaction between $\mathrm{BI}$ and $\mathrm{BA}$ to $\mathrm{DBI}$, as well as the following hydrogenation of DBI to DBA, were not calculated, because of the limitation of our computing resources for such large molecules (Fig. 4a).

On $\mathrm{Pd}(111)$, we found that the first hydrogenation of $\mathrm{BN}$ to the benzylideneimine (BI) intermediate, a key intermediate for DBA formation $^{27}$, is thermoneutral with an effective barrier of $1.32 \mathrm{eV}$. The following hydrogenation of BI to BA is slightly endothermic by $0.18 \mathrm{eV}$, but has a significantly lower effective barrier of $0.93 \mathrm{eV}$ (Fig. 4b, and see Supplementary Figs. 15 and 16 and Supplementary Note 3 for details). On Pt(111), the effective barriers of these two hydrogenation steps show an opposite trend to that on $\mathrm{Pd}(111)$ : the second hydrogenation step shows a considerably higher effective barrier $(1.20 \mathrm{eV})$ than the first step $(0.91 \mathrm{eV})$ (Fig. 4b, and see Supplementary Figs. 17 and 18 and
Supplementary Note 4 for details). These two consecutive hydrogenation steps are both exothermic by 0.44 and $0.49 \mathrm{eV}$, respectively. These results infer unambiguously that the considerably higher effective barrier for the second hydrogenation step on $\mathrm{Pt}(111)$ favors extending the resident time of the BI surface intermediate, thereby prompting the condensation reaction via nucleophilic attack of BI surface intermediate by BA to form the DBI intermediate (Fig. 4a) ${ }^{27,32}$. Subsequently, the DBI captures surface hydrogen atoms rapidly to produce the desired secondary amine (DBA) product on Pt catalysts ${ }^{35}$. On the contrary, the largely decreased effective barrier for the second hydrogenation step on $\mathrm{Pd}(111)$ shortens the resident time of the $\mathrm{BI}$ intermediate, and drives the reaction aggressively to the BA formation on Pd catalysts. These calculation results are in excellent consistence with our experimental results in Fig. 2a, b. Therefore, it is concluded that the relative difference of effective energy barriers of first two hydrogenation steps govern the 
documented metal-dependent selectivity by regulating the resident time of the BI intermediate. Further hydrogenolysis of BA to the undesired TOL by-product can certainly occur on both $\operatorname{Pd}(111)$ and $\mathrm{Pt}(111)$, since the corresponding barriers of 1.38 and $1.25 \mathrm{eV}$ are only slightly higher than the barriers of the two hydrogenation steps, which again consists excellently with the experimental results (Fig. 2a, b, f). To our best knowledge, this is the first theoretical view of the metal-selectivity relations on $\mathrm{Pd}$ and Pt surfaces in hydrogenation of BN.

In sharp contrast, on $\mathrm{Pd}_{1} @ \mathrm{Ni}(111) \mathrm{SASA}$, where the isolated $\mathrm{Pd}$ atoms are within the outmost layer of $\mathrm{Ni}$ lattices according to EXAFS analysis (Fig. 3a), the reaction profile changes dramatically (Fig. 4b and see Supplementary Figs. 19 and 20 and Supplementary Note 5 for detials): the hydrogenation of BN to the $\mathrm{BI}$ intermediate becomes more facile on $\mathrm{Pd}_{1} @ \mathrm{Ni}(111)$ (barrier $1.06 \mathrm{eV}$, exothermic $0.47 \mathrm{eV}$ ) than on $\mathrm{Pd}(111)$ (barrier $1.32 \mathrm{eV}$, exothermic $0 \mathrm{eV}$ ). On the contrary, the second hydrogenation step becomes more difficult with a considerably higher effective barrier of $1.30 \mathrm{eV}$. According to the knowledge learned on $\mathrm{Pd}$ (111) and $\mathrm{Pt}(111)$, facilitation of the first hydrogenation step but suppression of the second one would drastically improve the DBA formation, consistent with our experimental observation (Fig. 2c). Meanwhile, it is also found that the BI intermediate adsorbs considerably stronger on $\mathrm{Pd}_{1} @ \mathrm{Ni}(111)(2.74 \mathrm{eV})$ than on $\mathrm{Pd}(111)$ $(2.59 \mathrm{eV})$ and $\mathrm{Pt}(111)(2.08 \mathrm{eV})$ (Supplementary Fig. 21). Such stronger adsorption would reduce the mobility of BI on $\mathrm{Pd}_{1} @ \mathrm{Ni}$ (111) and further accelerate the condensation reaction. These findings provide a molecular-level insight of breaking the metaldependent selectivity in $\mathrm{BN}$ hydrogenation over $\mathrm{Pd}_{1} \mathrm{Ni}$ SASA. Besides above, benefiting from the surrounding Ni (Supplementary Figs. 21-23 and Supplementary Note 6), hydrogenolysis of $\mathrm{BA}$ on $\mathrm{Pd}_{1} @ \mathrm{Ni}(111)$ has a much higher barrier of $1.56 \mathrm{eV}$ than that on $\mathrm{Pd}(111)(1.38 \mathrm{eV})$ (Fig. 4b), again elucidating the effective inhibition of undesired hydrogenolysis of BA to TOL on $5 \mathrm{Pd}-\mathrm{Ni}$ / $\mathrm{SiO}_{2}$ (Fig. 2c, f). The electronic perturbation of $\mathrm{Pd}$ from the underlying $\mathrm{Ni}$ as suggested by XPS might play the important role (Fig. 3c).

However, the DFT results seem not elucidate the activity enhancement on $\mathrm{Pd}_{1} \mathrm{Ni}$ SASA on its own, since the highest effective energy barrier of $\mathrm{BN}$ hydrogenation to $\mathrm{BA}$ on $\mathrm{Pd}_{1} @ \mathrm{Ni}$ (111) surface $(1.30 \mathrm{eV})$ is very close to that on $\mathrm{Pd}(111)(1.32 \mathrm{eV})$ and $\operatorname{Pt}(111)$ surface $(1.20 \mathrm{eV})$. In fact, it is well-known that the hydrogenation activity not only depends on energetic profiles, but also correlates strongly with the competitive adsorption of substrate molecule and $\mathrm{H}_{2}{ }^{16}$. For bimetallic catalysts, hydrogen spillover could play very important roles for the activity enhancement ${ }^{39,72}$. For example, in hydrogenation of 3-nitrostyrene, Peng et al. reported that $\mathrm{Pt}_{1} \mathrm{Ni}$ SAA catalyst had a TOF of $\sim 1800 \mathrm{~h}^{-1}$, much higher than that of Pt single atoms supported on active carbon, $\mathrm{TiO}_{2}, \mathrm{SiO}_{2}$, and ZSM-5. The remarkable activity of $\mathrm{Pt}_{1} / \mathrm{Ni}$ nanocrystals was attributed to sufficient hydrogen supply because of spontaneous dissociation of $\mathrm{H}_{2}$ on both $\mathrm{Pt}$ and $\mathrm{Ni}$ atoms as well as facile diffusion of $\mathrm{H}$ atoms on $\mathrm{Pt}_{1} / \mathrm{Ni}$ nanocrystals ${ }^{72}$. In our work, we speculate that spontaneous dissociation of $\mathrm{H}_{2}$ on both $\mathrm{Pd}$ and $\mathrm{Ni}$ atoms provides a reservoir of active $\mathrm{H}$ atoms on $\mathrm{Pd}_{1} \mathrm{Ni}$ SASA surface, thus greatly accelerating the sequential hydrogenations.

Substrate exploration. Finally, we further evaluated the 5Pd-Ni/ $\mathrm{SiO}_{2}$ SASA sample in hydrogenation of a broad scope of nitrile substrates. As shown in Fig. 5, hydrogenation of aromatic nitriles with either electron-donating groups $\left(\mathrm{R}=\mathrm{CH}_{3}, \mathrm{OCH}_{3}\right)$ or electron-withdrawing groups $\left(\mathrm{R}=\mathrm{F}, \mathrm{CF}_{3}\right)$ and aliphatic nitriles, proceeded smoothly under mild conditions without any additives and leading to excellent yield of the corresponding secondary
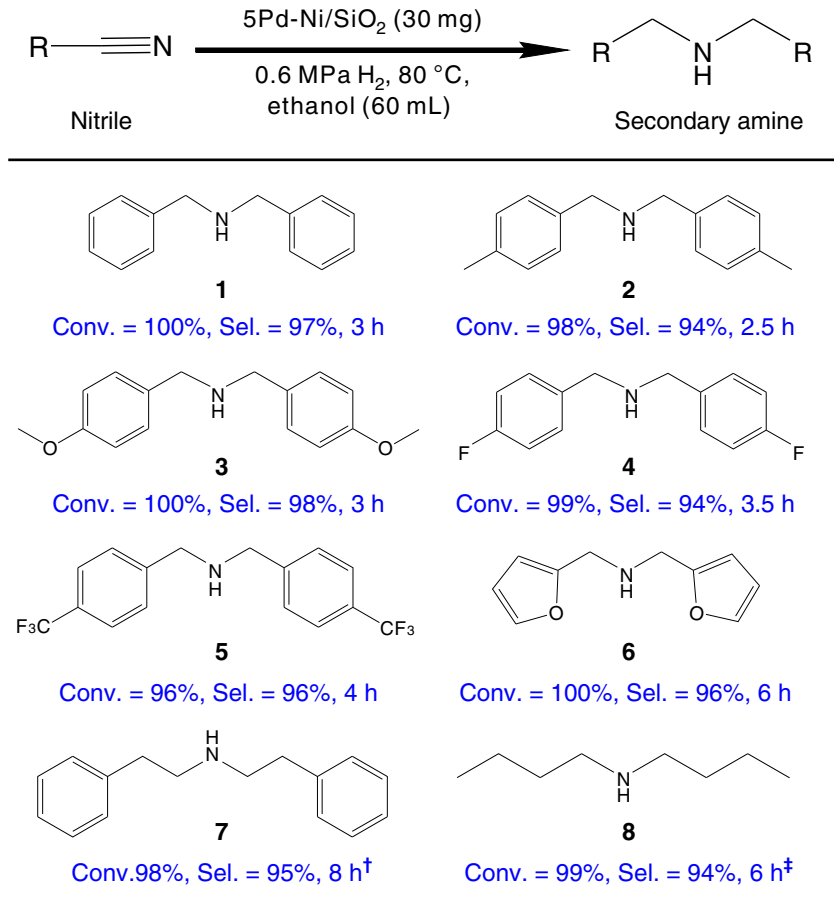

Fig. 5 Catalytic performance of $5 \mathrm{Pd}-\mathrm{Ni} / \mathrm{SiO}_{2}$ catalyst in hydrogenation of substituted nitriles. Reaction conditions: nitrile, $0.5 \mathrm{~g}$; ethanol, $60 \mathrm{~mL}$; catalyst, $30 \mathrm{mg}$; temperature, $80^{\circ} \mathrm{C} ; \mathrm{H}_{2}, 0.6 \mathrm{MPa}$. ${ }^{\dagger} 0.25 \mathrm{~g}$ nitrile, $65^{\circ} \mathrm{C}$. $0.125 \mathrm{~g}$ nitrile, $65^{\circ} \mathrm{C}$

amines above 94\%. The major by-products were the corresponding primary amines, while the hydrogenolysis by-products were completely inhibited in all cases, demonstrating the great potentials for industrial applications.

In summary, we have demonstrated that isolating $\mathrm{Pd}$ with $\mathrm{Ni}$ breaks the strong metal-selectivity relations in hydrogenation of nitriles, and prompts the yield of secondary amines drastically up to $>94 \%$ over a broad scope of nitriles under middle conditions. Meanwhile, the activity was also remarkably enhanced to about eight and four times higher than those of Pd and Pt catalysts, respectively. Importantly, the resulting materials also showed excellent recyclability and a complete inhibition of the formation of hydrogenolysis by-product, demonstrating the great potentials for practical applications. DFT calculations, to our best knowledge, provided the first theoretical view of the metal-selectivity relations on $\mathrm{Pd}$ and $\mathrm{Pt}$ surfaces, and unveiled the synergy in $\mathrm{Pd}_{1} \mathrm{Ni}$ SASA for the switch of reaction pathway from primary amines on Pd to the exclusive formation of secondary amines. It should be noted that selective Pd ALD is essential to achieve the high DBA yield with complete TOL inhibition, while such selective deposition might not be applicable to other supports such as $\mathrm{Al}_{2} \mathrm{O}_{3}$. Nonetheless, these findings open a promising avenue to rational design of metal catalyst with controlled selectivity and activity.

\section{Data availability}

The data underlying Figs. 1-5, Supplementary Figs. 2, 4-13, 16, 18, 20, and 23, DFT calculated XYZ coordination parameters of reactants, intermediates, products, and transition states on $\mathrm{Pd}(111), \operatorname{Pt}(111)$, and $\mathrm{Pd}_{1} @ \mathrm{Ni}(111)$ surfaces are provided as a Source Data file. The other data that support the findings of this study are available from the corresponding author upon request.

Received: 28 June 2019; Accepted: 9 October 2019; Published online: 01 November 2019 


\section{References}

1. Petranyi, G., Ryder, N. S. \& Stutz, A. Allylamine derivatives: new class of synthetic antifungal agents inhibiting fungal squalene epoxidase. Science 224, 1239-1241 (1984).

2. Nanavati, S. M. \& Silverman, R. B. Mechanisms of inactivation of $\gamma$ aminobutyric acid aminotransferase by the antiepilepsy drug $\gamma$-vinyl GABA (vigabatrin). J. Am. Chem. Soc. 113, 9341-9349 (1991).

3. Salvatore, R. N., Yoon, C. H. \& Jung, K. W. Synthesis of secondary amines. Tetrahedron 57, 7785-7811 (2001).

4. Bagal, D. B. \& Bhanage, B. M. Recent advances in transition metal-catalyzed hydrogenation of nitriles. Adv. Synth. Catal. 357, 883-900 (2015).

5. Werkmeister, S., Junge, K. \& Beller, M. Catalytic hydrogenation of carboxylic acid esters, amides, and nitriles with homogeneous catalysts. Org. Process Res. Dev. 18, 289-302 (2014).

6. Muller, T. E. \& Beller, M. Metal-initiated amination of alkenes and alkynes Chem. Rev. 98, 675-703 (1998).

7. Das, K. et al. Platinum-catalyzed direct amination of allylic alcohols with aqueous ammonia: selective synthesis of primary allylamines. Angew. Chem. Int. Ed. 51, 150-154 (2012).

8. Brown, B. R. The Organic Chemistry Of Aliphatic Nitrogen Compounds. Vol. 28 (Oxford University Press, 1994).

9. Hartwig, J. F. Transition metal catalyzed synthesis of arylamines and aryl ethers from aryl halides and triflates: scope and mechanism. Angew. Chem. Int. Ed. 37, 2046-2067 (1998).

10. Hartwig, J. F. Evolution of a fourth generation catalyst for the amination and thioetherification of aryl halides. Acc. Chem. Res. 41, 1534-1544 (2008).

11. Bissember, A. C., Lundgren, R. J., Creutz, S. E., Peters, J. C. \& Fu, G. C. Transition-metal-catalyzed alkylations of amines with alkyl halides: Photoinduced, copper-catalyzed couplings of carbazoles. Angew. Chem. Int. Ed. 52, 5129-5133 (2013).

12. Hahn, G., Kunnas, P., de Jonge, N. \& Kempe, R. General synthesis of primary amines via reductive amination employing a reusable nickel catalyst. Nat. Catal. 2, 71-77 (2018).

13. Murugesan, K., Beller, M. \& Jagadeesh, R. V. Reusable nickel nanoparticlescatalyzed reductive amination for selective synthesis of primary amines. Angew. Chem. Int. Ed. 58, 5064-5068 (2019).

14. Bähn, S. et al. The catalytic amination of alcohols. ChemCatChem 3, 1853-1864 (2011).

15. Zimmermann, B., Herwig, J. \& Beller, M. The first efficient hydroaminomethylation with ammonia: with dual metal catalysts and twophase catalysis to primary amines. Angew. Chem. Int. Ed. 38, 2372-2375 (1999).

16. Bakker, J. J. W., van der Neut, A. G., Kreutzer, M. T., Moulijn, J. A. \& Kapteijn, F. Catalyst performance changes induced by palladium phase transformation in the hydrogenation of benzonitrile. J. Catal. 274, 176-191 (2010).

17. Chen, F. et al. Stable and inert cobalt catalysts for highly selective and practical hydrogenation of $\mathrm{C} \equiv \mathrm{N}$ and $\mathrm{C}=\mathrm{O}$ bonds. J. Am. Chem. Soc. 138, 8781-8788 (2016).

18. De Bellefon, C. \& Fouilloux, P. Homogeneous and heterogeneous hydrogenation of nitriles in a liquid phase: chemical, mechanistic, and catalytic aspects. Catal. Rev. 36, 459-506 (1994).

19. Hegedüs, L. \& Máthé, T. Selective heterogeneous catalytic hydrogenation of nitriles to primary amines in liquid phase: part I. Hydrogenation of benzonitrile over palladium. Appl. Catal. A 296, 209-215 (2005).

20. McMillan, L. et al. The application of a supported palladium catalyst for the hydrogenation of aromatic nitriles. J. Mol. Catal. A Chem. 411, 239-246 (2016).

21. Lu, S. L., Wang, J. Q., Cao, X. Q., Li, X. M. \& Gu, H. W. Selective synthesis of secondary amines from nitriles using $\mathrm{Pt}$ nanowires as a catalyst. Chem. Commun. 50, 3512-3515 (2014).

22. Greenfield, H. Hydrogenation of benzonitrile to dibenzylamine. Ind. Eng. Chem. Prod. Res. Dev. 15, 156-158 (1976).

23. Galan, A., De Mendoza, J., Prados, P., Rojo, J. \& Echavarren, A. M. Synthesis of secondary amines by rhodium catalyzed hydrogenation of nitriles. J. Org. Chem. 56, 452-454 (1991).

24. Reguillo, R., Grellier, M., Vautravers, N., Vendier, L. \& Sabo-Etienne, S. Ruthenium-catalyzed hydrogenation of nitriles: insights into the mechanism. J. Am. Chem. Soc. 132, 7854-7855 (2010).

25. Bornschein, C. et al. Mild and selective hydrogenation of aromatic and aliphatic (di)nitriles with a well-defined iron pincer complex. Nat. Commun. 5, 4111 (2014).

26. Elangovan, S. et al. Selective catalytic hydrogenations of nitriles, ketones, and aldehydes by well-defined manganese pincer complexes. J. Am. Chem. Soc. 138, 8809-8814 (2016)

27. Braun, J. V., Blessing, G. \& Zobel, F. Katalytische hydrierungen unter druck bei gegenwart von nickelsalzen, VI.: nitrile. Ber. dtsch. Chem. Ges. 56, 1988-2001 (1923).
28. Gomez, S., Peters, J. A. \& Maschmeyer, T. The reductive amination of aldehydes and ketones and the hydrogenation of nitriles: mechanistic aspects and selectivity control. Adv. Synth. Catal. 344, 1037-1057 (2002).

29. McMichael, A. Carcinogenicity of benzene, toluene and xylene: epidemiological and experimental evidence. IARC Sci. Publ. 85, 3-18 (1988).

30. Cheng, H. et al. Selective hydrogenation of benzonitrile in multiphase reaction systems including compressed carbon dioxide over $\mathrm{Ni} / \mathrm{Al}_{2} \mathrm{O}_{3}$ catalyst. J. Mol. Catal. A Chem. 379, 72-79 (2013).

31. Dai, C. et al. Efficient and selective hydrogenation of benzonitrile to benzylamine: improvement on catalytic performance and stability in a tricklebed reactor. New J. Chem. 41, 3758-3765 (2017).

32. López-De Jesús, Y. M., Johnson, C. E., Monnier, J. R. \& Williams, C. T. Selective hydrogenation of benzonitrile by alumina-supported $\mathrm{Ir}-\mathrm{Pd}$ catalysts. Top. Catal. 53, 1132-1137 (2010).

33. Hartung, W. H. Catalytic reduction of nitriles and oximes. J. Am. Chem. Soc. 50, 3370-3374 (1928).

34. Chatterjee, M. et al. Hydrogenation of nitrile in supercritical carbon dioxide: a tunable approach to amine selectivity. Green. Chem. 12, 87-93 (2010).

35. Liu, L. et al. Pd-CuFe catalyst for transfer hydrogenation of nitriles: controllable selectivity to primary amines and secondary amines. iScience $\mathbf{8}$, 61-73 (2018).

36. Liu, L. et al. A ppm level Rh-based composite as an ecofriendly catalyst for transfer hydrogenation of nitriles: triple guarantee of selectivity for primary amines. Green Chem. 21, 1390-1395 (2019).

37. Li, J. et al. Moderate activity from trace palladium alloyed with copper for the chemoselective hydrogenation of $-\mathrm{CN}$ and $-\mathrm{NO}_{2}$ with $\mathrm{HCOOH}$. ChemistrySelect 4, 7346-7350 (2019).

38. Shao, Z., Fu, S., Wei, M., Zhou, S. \& Liu, Q. Mild and selective cobalt-catalyzed chemodivergent transfer hydrogenation of nitriles. Angew. Chem. Int. Ed. 55, 14653-14657 (2016)

39. Kyriakou, G. et al. Isolated metal atom geometries as a strategy for selective heterogeneous hydrogenations. Science 335, 1209-1212 (2012).

40. Lucci, F. R. et al. Selective hydrogenation of 1,3-butadiene on platinum-copper alloys at the single-atom limit. Nat. Commun. 6, 8550 (2015).

41. Pei, G. X. et al. Ag alloyed Pd single-atom catalysts for efficient selective hydrogenation of acetylene to ethylene in excess ethylene. ACS Catal. 5, 3717-3725 (2015)

42. Sun, G. et al. Breaking the scaling relationship via thermally stable $\mathrm{Pt} / \mathrm{Cu}$ single atom alloys for catalytic dehydrogenation. Nat. Commun. 9, 4454 (2018).

43. Ge, J. et al. Atomically dispersed $\mathrm{Ru}$ on ultrathin Pd nanoribbons. J. Am. Chem. Soc. 138, 13850-13853 (2016).

44. Feng, Q. et al. Isolated single-atom Pd sites in intermetallic nanostructures: high catalytic selectivity for semihydrogenation of alkynes. J. Am. Chem. Soc 139, 7294-7301 (2017).

45. Marcinkowski, M. D. et al. Pt/Cu single-atom alloys as coke-resistant catalysts for efficient C-H activation. Nat. Chem. 10, 325-332 (2018).

46. Maeda, K. et al. Dibenzylamine compounds and pharmaceutical use thereof US Patent 7,807,701 B2 (2010).

47. Buckwalter, F. H. Dibenzylamine salts of penicillin. US Patent 2,585,432 A (1952).

48. Burattin, P., Che, M. \& Louis, C. Metal particle size in $\mathrm{Ni} / \mathrm{SiO}_{2}$ materials prepared by deposition-precipitation: Influence of the nature of the $\mathrm{Ni}$ (II) phase and of its interaction with the support. J. Phys. Chem. B 103, 6171-6178 (1999).

49. Lu, J. L. et al. Toward atomically-precise synthesis of supported bimetallic nanoparticles using atomic layer deposition. Nat. Commun. 5, 3264 (2014).

50. Wang, H. W., Wang, C. L., Yan, H., Yi, H. \& Lu, J. L. Precisely-controlled synthesis of Au@Pd core-shell bimetallic catalyst via atomic layer deposition for selective oxidation of benzyl alcohol. J. Catal. 324, 59-68 (2015).

51. Cao, L. et al. Atomically dispersed iron hydroxide anchored on Pt for preferential oxidation of $\mathrm{CO}$ in $\mathrm{H}_{2}$. Nature 565, 631-635 (2019).

52. Chen, $\mathrm{X}$. et al. Solvent-driven selectivity control to either anilines or dicyclohexylamines in hydrogenation of nitroarenes over a bifunctional $\mathrm{Pd} /$ MIL-101 catalyst. ACS Catal. 8, 10641-10648 (2018).

53. Hou, R. J., Porosoff, M. D., Chen, J. G. \& Wang, T. F. Effect of oxide supports on Pd-Ni bimetallic catalysts for 1,3-butadiene hydrogenation. Appl. Catal. A 490, 17-23 (2015)

54. Nurunnabi, M. et al. Oxidative steam reforming of methane under atmospheric and pressurized conditions over $\mathrm{Pd} / \mathrm{NiO}-\mathrm{MgO}$ solid solution catalysts. Appl. Catal. A 308, 1-12 (2006).

55. Aich, P. et al. Single-atom alloy Pd-Ag catalyst for selective hydrogenation of acrolein. J. Phys. Chem. C 119, 18140-18148 (2015).

56. Mori, K., Hara, T., Mizugaki, T., Ebitani, K. \& Kaneda, K. Hydroxyapatitesupported palladium nanoclusters: a highly active heterogeneous catalyst for selective oxidation of alcohols by use of molecular oxygen. J. Am. Chem. Soc. 126, 10657-10666 (2004). 
57. Pei, G. X. et al. Performance of Cu-alloyed Pd single-atom catalyst for semihydrogenation of acetylene under simulated front-end conditions. ACS Catal. 7, 1491-1500 (2017).

58. Lear, T. et al. The application of infrared spectroscopy to probe the surface morphology of alumina-supported palladium catalysts. J. Chem. Phys. 123, 174706 (2005).

59. Yudanov, I. V. et al. CO adsorption on Pd nanoparticles: Density functional and vibrational spectroscopy studies. J. Phys. Chem. B 107, 255-264 (2003).

60. Zhang, L. et al. Efficient and durable Au alloyed Pd single-atom catalyst for the Ullmann reaction of aryl chlorides in water. ACS Catal. 4, 1546-1553 (2014).

61. Lu, J. et al. Coking- and sintering-resistant palladium catalysts achieved through atomic layer deposition. Science 335, 1205-1208 (2012).

62. Xin, P. et al. Revealing the active species for aerobic alcohol oxidation by using uniform supported palladium catalysts. Angew. Chem. Int. Ed. 57, 4642-4646 (2018).

63. Wei, X. et al. Bimetallic Au-Pd alloy catalysts for $\mathrm{N}_{2} \mathrm{O}$ decomposition: Effects of surface structures on catalytic activity. J. Phys. Chem. C 116, 6222-6232 (2012).

64. Bertolini, J. C., Miegge, P., Hermann, P., Rousset, J. L. \& Tardy, B. On the reactivity of $2 \mathrm{~d}$ Pd surface alloys obtained by surface segregation or deposition technique. Surf. Sci. 331, 651-658 (1995).

65. Hermann, P., Simon, D. \& Bigot, B. Pd deposits on Ni(111): a theoretical study. Surf. Sci. 350, 301-314 (1996).

66. Hermann, P. et al. The Pd/Ni (110) bimetallic system: Surface characterisation by LEED, AES, XPS, and LEIS techniques; new insight on catalytic properties. J. Catal. 163, 169-175 (1996).

67. Nutt, M. O., Heck, K. N., Alvarez, P. \& Wong, M. S. Improved Pd-on-Au bimetallic nanoparticle catalysts for aqueous-phase trichloroethene hydrodechlorination. Appl. Catal. B 69, 115-125 (2006).

68. Carlsson, A. F., Naschitzki, M., Bäumer, M. \& Freund, H.-J. The structure and reactivity of $\mathrm{Al}_{2} \mathrm{O}_{3}$-supported cobalt- palladium particles: A CO-TPD, STM, and XPS study. J. Phys. Chem. B 107, 778-785 (2003).

69. Lozano-Blanco, G. \& Adamczyk, A. J. Cobalt-catalyzed nitrile hydrogenation: Insights into the reaction mechanism and product selectivity from DFT analysis. Surf. Sci. 688, 31-44 (2019).

70. Adamczyk, A. J. First-principles analysis of acetonitrile reaction pathways to primary, secondary, and tertiary amines on Pd (111). Surf. Sci. 682, 84-98 (2019).

71. Lozano-Blanco, G., Tatarchuk, B. J. \& Adamczyk, A. J. Building a microkinetic model from first principles for higher amine synthesis on Pd catalyst. Ind. Eng. Chem. Res. https://doi.org/10.1021/acs.iecr.9b03577 (2019).

72. Peng, Y. et al. Pt single atoms embedded in the surface of Ni nanocrystals as highly active catalysts for selective hydrogenation of nitro compounds. Nano Lett. 18, 3785-3791 (2018).

\section{Acknowledgements}

This work was supported by the National Natural Science Foundation of China (Grants 21673215, 21688102, and 21703222), the National Key Research \& Development Program of China (Grant 2016YFA02006), the Fundamental Research Funds for the Central
Universities (WK2060030029), Users with Excellence Program of Hefei Science Center CAS (2019HSC-UE016), and the Max-Planck Partner Group. The calculations were performed on the supercomputing system in the Supercomputing Center of University of Science and Technology of China and the High-performance Computing Platform of Anhui University. The authors also gratefully thank the BL14W1 beamline at the Shanghai Synchrotron Radiation Facility (SSRF), the BL10B beamline at National Synchrotron Radiation Laboratory (NSRL), China.

\section{Author contributions}

J.L. designed the experiments; H.W. synthesized and characterized the catalysts and performed the catalytic performance evaluation; H.W., S.W., W.L., and Z.S. performed the XAFS measurements; H.W. X.Z., H.P., and J.Z. did the XPS characterization; Y.L. did the STEM measurements; Q.G. helped catalyst synthesis; Q.L. and J.Y. did the DFT calculations; J.L. and H.W. co-wrote the manuscript, and all the authors contributed to the overall scientific interpretation and edited the manuscript.

\section{Competing interests}

The authors declare no competing interests.

\section{Additional information}

Supplementary information is available for this paper at https://doi.org/10.1038/s41467 019-12993-x.

Correspondence and requests for materials should be addressed to J.L.

Peer review information Nature Communications thanks Andrew Adamczyk, Hongbin Sun and other, anonymous, reviewers for their contributions to the peer review of this work. Peer review reports are available.

Reprints and permission information is available at http://www.nature.com/reprints

Publisher's note Springer Nature remains neutral with regard to jurisdictional claims in published maps and institutional affiliations.

\begin{abstract}
(c) (i) Open Access This article is licensed under a Creative Commons BY Attribution 4.0 International License, which permits use, sharing, adaptation, distribution and reproduction in any medium or format, as long as you give appropriate credit to the original author(s) and the source, provide a link to the Creative Commons license, and indicate if changes were made. The images or other third party material in this article are included in the article's Creative Commons license, unless indicated otherwise in a credit line to the material. If material is not included in the article's Creative Commons license and your intended use is not permitted by statutory regulation or exceeds the permitted use, you will need to obtain permission directly from the copyright holder. To view a copy of this license, visit http://creativecommons.org/ licenses/by/4.0/.
\end{abstract}

(C) The Author(s) 2019 